\title{
Board 13: Manufacturing Division: Improving Student Engagement in a Senior-Level Manufacturing Course for Mechanical Engineering Students
}

\section{Dr. Joshua Gargac, University of Mount Union}

Joshua Gargac is an assistant professor of mechanical engineering at the University of Mount Union in Alliance, $\mathrm{OH}$, where he advises the mechanical engineering senior capstone projects and SAE Baja team. In addition, Dr. Gargac teaches first-year engineering courses, computer-aided design, kinematics and dynamics of machinery, and manufacturing science. He received his BSME from Ohio Northern University and a PhD in Bioengineering from the University of Notre Dame. Current interests include bone tissue mechanics, engineering pedagogy, and robotic football. 


\section{Improving Student Engagement in a Senior-Level Manufacturing Course for Mechanical Engineering Students}

\section{Dr. Joshua Gargac, University of Mount Union}

Joshua Gargac is an assistant professor of mechanical engineering at the University of Mount Union in Alliance, $\mathrm{OH}$, where he advises the mechanical engineering senior capstone projects and SAE Baja team. In addition, Dr. Gargac teaches first year engineering courses, computer-aided design, kinematics and dynamics of machinery, and manufacturing science. He received his BSME from Ohio Northern University and a Ph.D in Bioengineering from the University of Notre Dame. Current interests include bone tissue mechanics, engineering pedagogy, and robotic football. 


\section{Improving Student Engagement in a Senior-level Manufacturing Course for Mechanical Engineering Students}

\section{Introduction:}

The mechanical engineering curriculum prepares students for employment in a broad range of industries [1]. In the Midwest, many graduating mechanical engineering students will find employment in manufacturing-related fields. This is especially true in Ohio, where $17.8 \%$ of the total gross state product is accounted for by over 12,000 manufacturing firms [2]. For this reason, manufacturing courses play an important role in preparing mechanical engineering students to succeed in these industries.

While most engineering courses are calculation- or design-intensive, manufacturing courses tend to be primarily information-driven. Covering this content through traditional lecturing often fails to fully engage student interest, motivation and learning potential. Research on student engagement in higher education indicates that improvements to course design and content delivery can improve student engagement [3-7]. Recommendations to instructors include developing interactive course activities [4], incorporating online multimedia resources [5-7], and integrating practical experiences into the delivery of the course content [7].

The purpose of this paper is to describe and evaluate the changes made to a traditional manufacturing lecture course that sought to improve student engagement and learning. The new course structure consisted of four components: 1) self-learning outside the classroom, 2) handson manufacturing experiences, 3) a lecture incorporating active-learning exercises, and 4) a TED Talk-style final presentation.

\section{Student and Course Background:}

The University of Mount Union is a private, liberal arts institution located in Alliance, $\mathrm{OH}$. The Engineering Department offers ABET-accredited undergraduate degree programs in mechanical and civil engineering. Of the nearly 2200 students enrolled at Mount Union, approximately 130 are majoring in one of the engineering disciplines.

A manufacturing science course is required for mechanical engineering students during the spring semester of their final year. The course is comprised of a 2-credit-hour course lecture and a 1-credit laboratory. Before spring semester of 2017, the course followed a more traditional structure. Readings were assigned out of a manufacturing textbook, the manufacturing processes were described during traditional academic lectures, and tests were proctored to assess student learning. The 1-credit-hour lab was used to tour five local manufacturing facilities throughout the semester. A comparison between the 2016 and 2017 course structure is shown in Figure 1. 

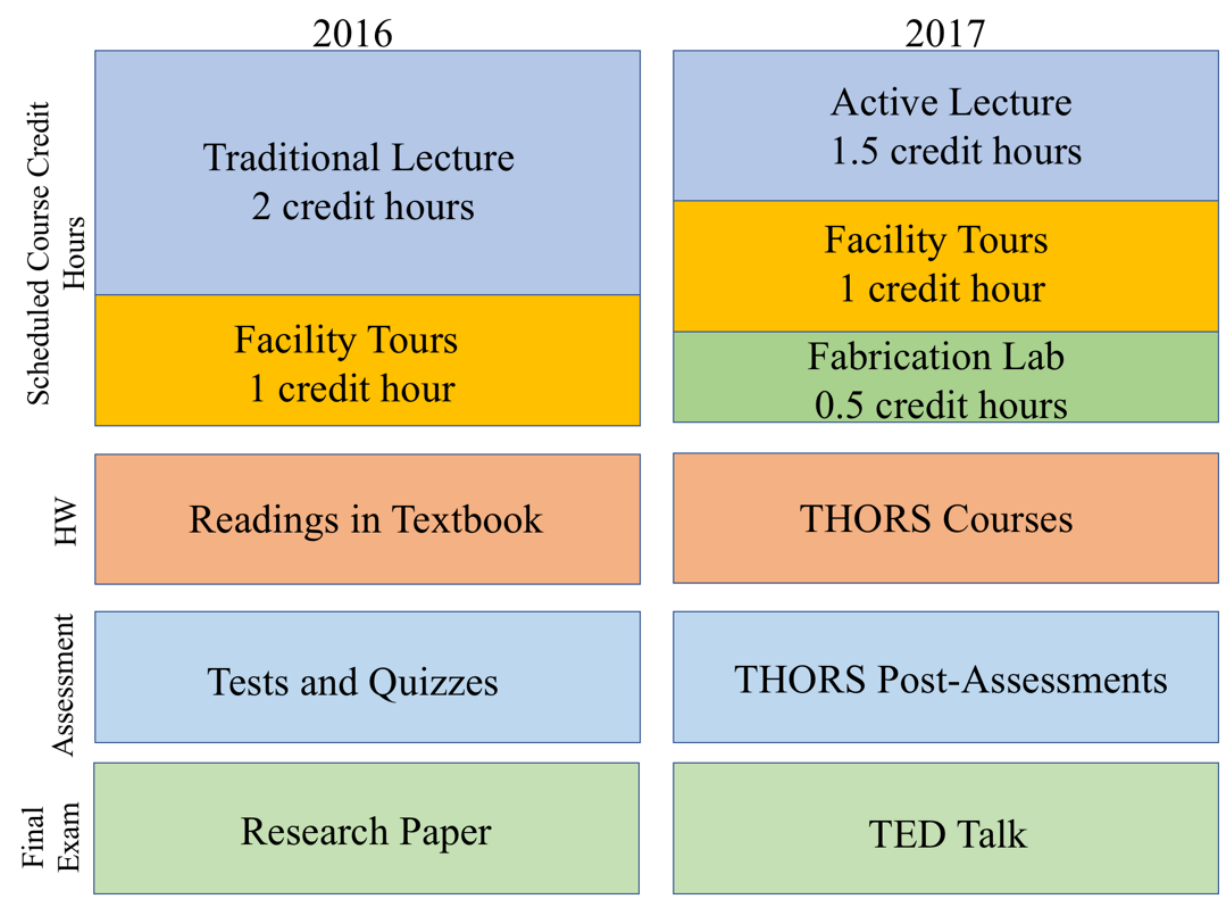

Figure 1: Comparative course structure between the 2016 and 2017 version of the course.

During the spring 2017 semester, 14 senior-level, male mechanical engineering students were enrolled in the course, of which two (14\%) identified as an underrepresented minority and one (7\%) as an international student. On pre-course surveys, eight students (57\%) listed a previous internship in a manufacturing-related area with five (36\%) indicating hands-on experience with manufacturing equipment. The remaining 6 students (43\%) listed no previous manufacturing experience.

\section{Course Components}

\section{Self-Learning Component:}

As the first major change to the course, the textbook was replaced with an online manufacturing learning resource, THORS Academy (THORS eLearning Solutions, Medina, $\mathrm{OH}$ ). The THORS Academy (THORS) consists of online courses designed to provide in-depth manufacturing knowledge to individuals working in or with the manufacturing industry, including business professionals, engineers, skilled laborers, and entry-level employees [8]. Primarily, THORS was designed to train employees working with different manufacturing processes including foundry, forging, and machining. A standard THORS course is organized into 3 components: 1) PreAssessment, 2) Course Content, and 3) Post-Assessment.

The Pre-Assessment consists of a quiz, typically between 15-25 questions, covering the contents and learning objectives of the course. In addition to providing a baseline for future assessment, the Pre-Assessment functioned to introduce course content, assess prior knowledge, and motivate students to seek out new knowledge. 
The Course Content module is organized into into discrete topic sections and relevant information is delivered using interactive, multimedia methods. THORS contains nearly 3,000 videos and animations integrated into its courses to demonstrate the specific processes [8]. An example Course Content module interface is shown in Figure 2A. These courses range in length and can take as long as 15 hours to complete, but most courses fall within the 2-6 hour range. A five-question quiz follows each topic section to review important concepts.

The Post-Assessment is similar to the Pre-Assessment in structure, but can only be attempted after the student views the entire Course Content module. To pass the THORS course, a minimum score of $80 \%$ is required on the Post-Assessment. If an $80 \%$ is not achieved, the students are directed back to review the sections in the Course Content module on which they tested poorly. Afterward revisiting these sections, the student can retry the Post-Assessment. An example question from the Post-Assessment is shown in Figure 2B.

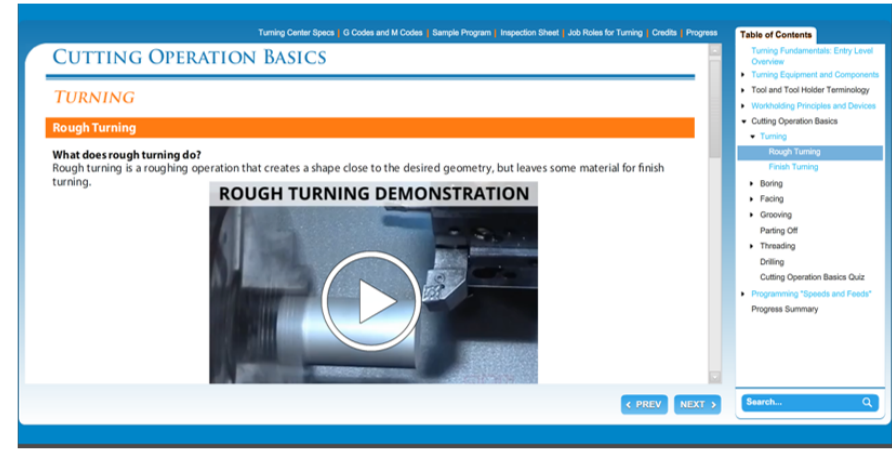

(A)

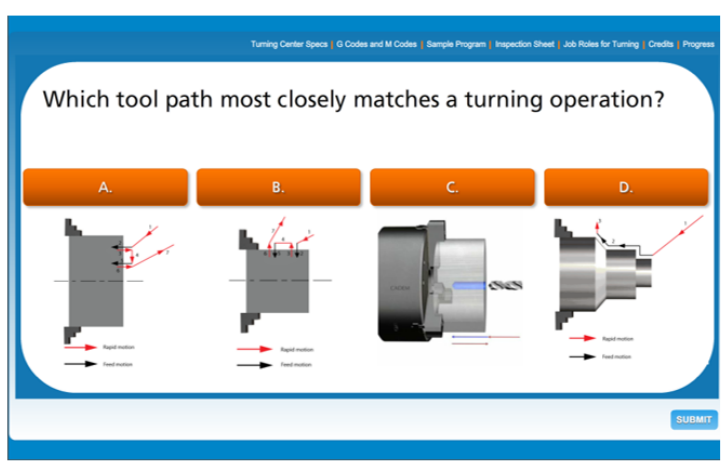

(B)

Figure 2: Example of THORS interface for Course Content (A) and Post-Assessment (B) [9]. *Used with permission from THORS eLearning Solutions.

In lieu of homework assignments, students were assigned THORS courses (Tab. 1) corresponding to hands-on and active lecture components. Students were given 3 weeks to complete each course. Their Post-Assessment score was established as the grade for the selflearning component of the course. 
Table 1: THORS courses assigned during semester. Students were given 3 weeks to complete each course.

\begin{tabular}{|c|c|l|c|}
\hline THORS Course Name & $\begin{array}{c}\text { Course } \\
\text { Length (hrs) }\end{array}$ & Corresponding Lecture Topic & $\begin{array}{c}\text { Assignment } \\
\text { Length (wks) }\end{array}$ \\
\hline Machining Foundation & 8.5 & $\begin{array}{l}\text { Cutting Dynamics } \\
\text { Fabrication Laboratory }\end{array}$ & 3 \\
\hline Heat Treating Fundamentals & 6 & $\begin{array}{l}\text { Finishing Operations } \\
\text { Forming and Shaping Processes } \\
\text { Heat Treatment Facility Tour }\end{array}$ & 3 \\
\hline Bonded Sand Molding & 14.5 & $\begin{array}{l}\text { Casting Processes } \\
\text { Steel Casting Facility Tour }\end{array}$ & 3 \\
\hline Stamping Fundamentals & 4 & Forming and Shaping Processes & 3 \\
\hline Polymer Fundamentals & 4 & $\begin{array}{l}\text { Polymer Manufacturing } \\
\text { Additive Manufacturing }\end{array}$ & 3 \\
\hline
\end{tabular}

\section{Hands-on Component:}

The hands-on component of the course was comprised of a fabrication laboratory in the machine shop and tours of local manufacturing facilities. The manufacturing facility tours were continued unchanged from the previous years and included tours to five different manufacturing facilities within 40 miles of the university (Tab. 2). After each tour, students were assigned a reflection essay describing what they learned on the tour.

Table 2: Manufacturing Facility Tours

\begin{tabular}{|l|c|}
\hline \multicolumn{1}{|c|}{ Facility Type } & $\begin{array}{c}\text { Week of } \\
\text { Semester }\end{array}$ \\
\hline $\begin{array}{l}\text { Continuous Steel } \\
\text { Production }\end{array}$ & 7 \\
\hline Heat Treatment of Metals & 8 \\
\hline Saw Blade Manufacturing & 12 \\
\hline $\begin{array}{l}\text { Additive Manufacturing } \\
\text { Innovation Center }\end{array}$ & 14 \\
\hline Polymer Injection Molding & 15 \\
\hline
\end{tabular}


Since, the use of THORS allowed for a "flipped classroom," where content was delivered to the students outside of classroom, scheduled course meetings could be spent on additional hands-on activities [10]. This allowed for four weeks of lecture to be replaced with four fabrication lab exercises: 1) milling, 2) turning, 3) welding, and 4) tapping and threading (Fig. 3). Through these activities, students were introduced to the basic use of the equipment (Fig. 4) while machining simple aluminum components and welding A36 structural steel. Lab activities were completed in pairs during timeslots spaced 1 hour apart.

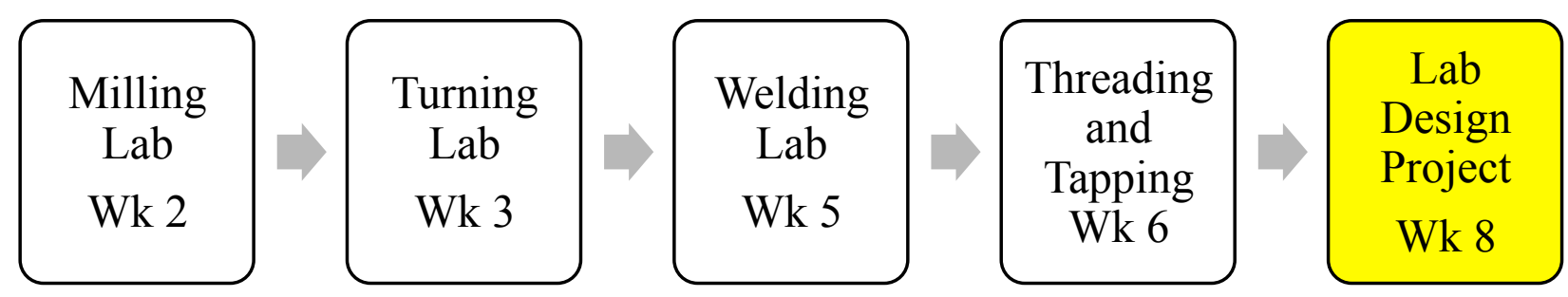

Figure 3: The fabrication laboratory consisted of hands-on experience with four unique manufacturing processes. The experience culminated with a lab-based design project.

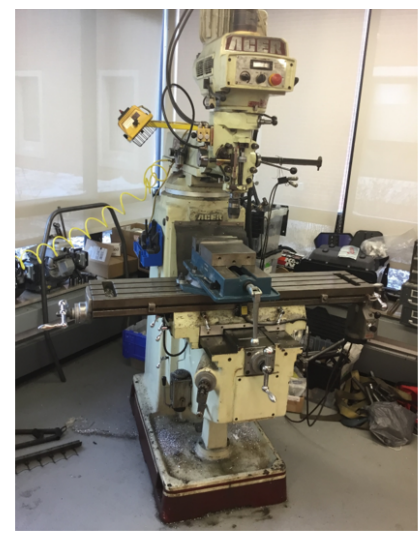

A

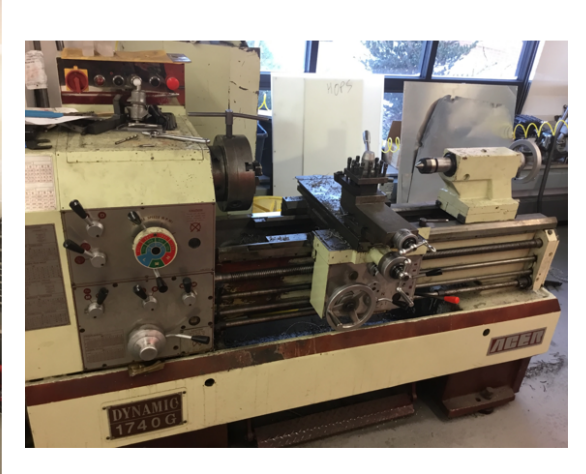

B

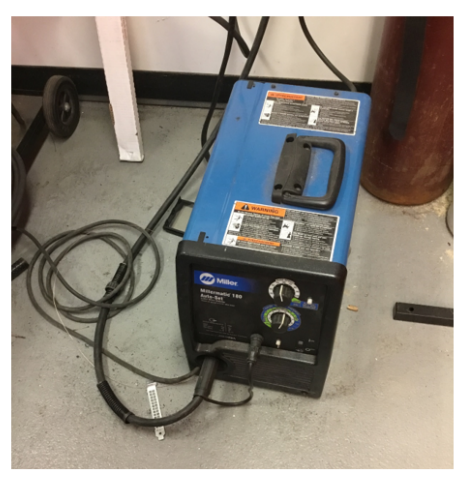

C

Figure 4: Fabrication lab equipment included A) an Acer vertical turret milling machine (3VKH), B) an Acer high precision engine lathe (Dynamic 1740G), and gas metal arc welding (GMAW) using a Miller power source (Millermatic 180 Autoset).

After the fabrication labs were completed, a culminating design project was assigned to synthesize the knowledge from the four labs. Students worked in pairs to design a product that could be fabricated and assembled using the equipment worked with during the labs. Each design had to satisfy the following constraints:

- The assembly must be completed in 4-5 lab sections (approximately 5 hours of work).

- The assembly must include milling, turning, welding, tapping, and threading components.

- One additional lab period could be added if needed.

- Additional pieces of equipment could be used, but they must already be at the university.

- Similar materials must be used: aluminum for machining and steel for welding.

- The cost of the materials should not be significantly increased from the current year's lab. 
Each team submitted a report describing the proposed product and the sequence of lab activities needed to fabricate each component. Each team also presented a 5-minute "sales pitch" to their classmates. The students peer evaluated the projects in four categories: feasibility, cost, presentation quality, and appeal. The highest scoring project (Fig. 5) was created in the fabrication lab the following year (spring semester 2018). Overall, the reflection essays and design project established the grade for the hands-on component.

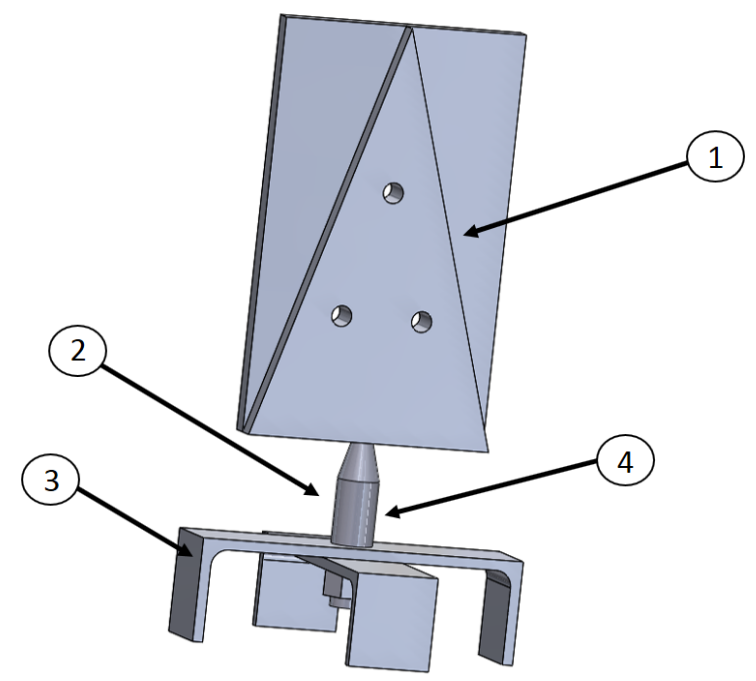

Figure 5: The winning lab design project was a Christmas Tree consisting of a milled aluminum "tree" (1), turned aluminum "trunk $\}$ (2), and a welded steel "tree stand" (3). The trunk was threaded (4) and the tree was assembled in during the fourth fabrication lab.

\section{Lecture Component:}

For processes not covered in the THORS course, content was delivered during regularly scheduled lectures. However, these course meetings were updated to improve student engagement and motivation. Williams and Williams recommend integrating online media into the delivery of course content to improve student engagement [7]. Therefore, traditional PowerPoint presentations were supplemented with videos detailing manufacturing processes. The availability of these videos on YouTube allowed for demonstrations of complex manufacturing processes without leaving the room. Student interviews conducted by Savage et al. revealed that PowerPoint-intensive lectures can negatively affect a student's motivation to learn [11]. In an effort to improve student engagement, active learning activities and guest speakers were incorporated into the course meetings.

As a practical application of the course material, the students engaged in "How's it Made?" activities. Working in teams of 3-4, students competed to identify the manufacturing processes used to fabricate metallic and polymer objects (Fig. 6) by observing the object's shape, surface finish, and function. When learning about additive manufacturing (AM), the students were assigned an internet-based "scavenger hunt" to determine the differences between popular AM processes. 
During the spring 2017 semester, three experts working in industry were invited to give guest lectures. These speakers addressed the following topics: welding processes in industry, advances in heat treatment of metals, and succeeding as an engineer in a manufacturing industry. When these guests lectured, each student was required to ask at least one question and then write a reflection essay describing what they learned about possible applications to their future engineering careers.

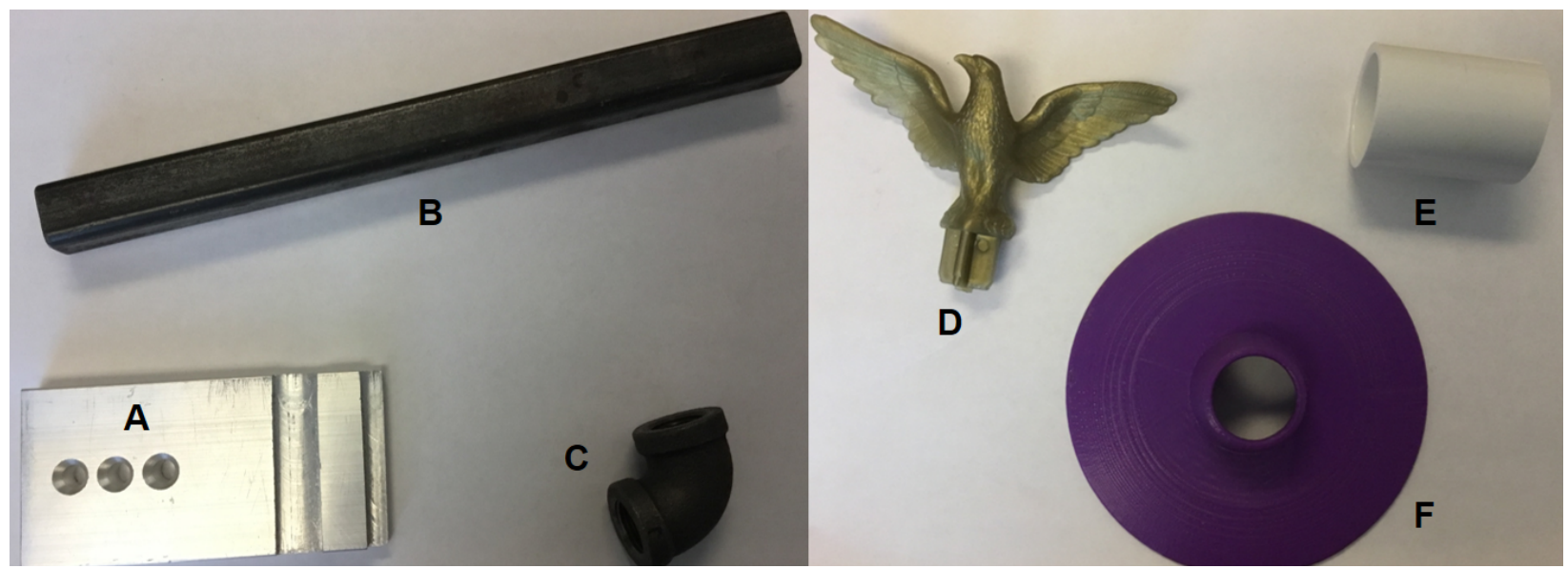

Figure 6: Example "How's it Made" objects. Some metallic objects included an A) aluminum bracket (milling), B) steel square tubing (hot rolling, welding), and C) an elbow pipe fitting (casting, tapping). Example polymer objects include D) an eagle-shaped inset (injection molding), E) a section of PVC pipe (extrusion), and F) a disk mount (additive manufacturing: Fused Deposition Modeling).

\section{Final Presentation:}

Since it is not possible to cover all manufacturing-related topics in a 2-credit hour course, a research project was integrated into the 2016 version of the course. For this project, students were given the opportunity to research manufacturing topics of personal interest that were not addressed in other course content. During the 2017 course, this final project was adapted into a TED Talk-style presentation [12]. This project was modeled with permission from a biomechanics project originally presented by Kuxhaus [13].

The manufacturing TED Talk was assigned 4 weeks before the final exam period. Students were provided an entire lecture meeting to complete a brainstorming worksheet. Potential projects were identified from broad categories including challenges facing the growth of manufacturing in the United States, advances in manufacturing technology, the application of manufacturing in specific interest areas (i.e. biomedical, aerospace, etc), and the description of manufacturing processes not already covered by the other course content.

Each student was then required to develop a 5-minute TED Talk about their chosen topic. The students were permitted one powerpoint slide to use as a visual aid to be displayed during their talk. The final exam period was organized as a mini-TED Conference during which the students 
presented their manufacturing TED Talks to faculty and their peers. The TED Talks were evaluated on the basis of presentation quality, organization, content, and originality.

\section{Data Analysis}

\section{THORS Academy}

Student learning in the self-learning component was tracked by comparing Pre-Assessment scores to Post-Assessment scores for each THORS course (Fig. 7). On average, students improved upon their Pre-Assessment score by $44( \pm 13)$ percentage points after completing the Course Content modules. In additional to topic mastery, the THORS course also increased student engagement. At the conclusion of the semester, students were surveyed with the following question: "Do you recommend that I use these again or should I return to a normal textbook?" Overall, 13 students (93\%) recommended the continued use of THORS in place of a manufacturing textbook.

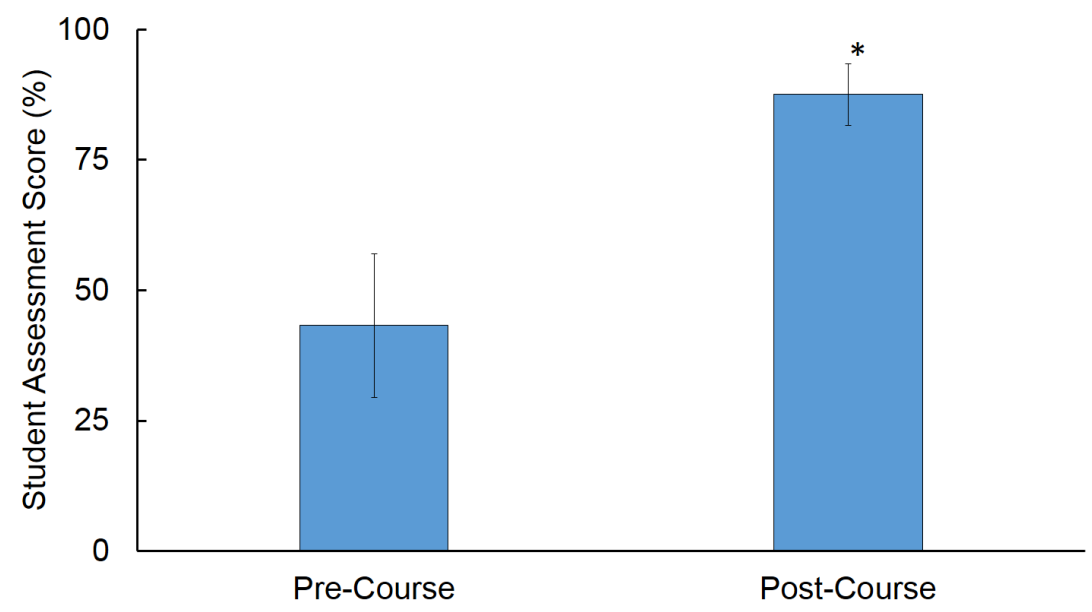

Figure 7: Post Assessment scores were $44( \pm 13)$ percentage points higher than the assessments taken before course participation. ${ }^{*} p<0.05$

\section{Course Design}

To quantify student attitudes regarding the changes integrating into to the course, each student was surveyed following their TED Talk presentations. Students were asked to list their three favorite aspects of the course. A histogram of student responses is shown in Figure 8. Overall, the manufacturing facility tours were the most frequent response (10 students). The use of THORS academy was the second most frequent response ( 7 students), followed by the fabrication lab (6 students) and the active lectures ( 6 students) respectively. The active lecture category included responses listing either specific lecture activities or individual topics that were covered. One student listed that the "course prepared me for my future," which is represented by Other. 


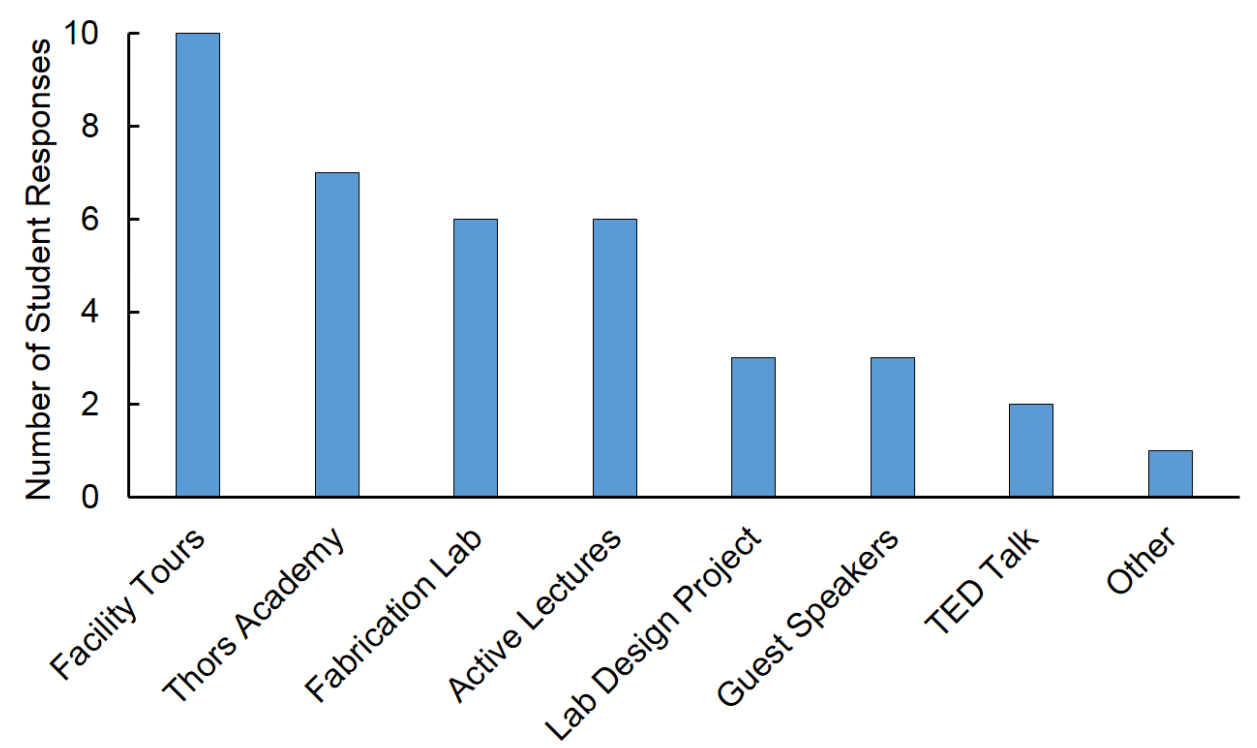

Figure 8: Frequency of course components listed as a student's favorite three aspects of the manufacturing course.

Student attitudes about the new course $(2017 ; \mathrm{n}=14)$ were also compared to those taking the course before the changes were made $(2016 ; \mathrm{n}=10)$. Evaluation scores from the university's Student Evaluation of Instructor and Course were gathered for seven questions relating to the students' attitude toward the course structure and content delivery (Tab. 3). Each evaluation was scored as Strongly Agree (4), Agree (3), Disagree (2), or Strongly Disagree (1). Evaluation scores were improved in all categories under the new course structure (Fig. 9). Overall, the greatest increases were observed for evaluation $3(16 \%)$, "The instructor cared about my learning in the course" and evaluation 4 (14\%) "The instructor motivated me to learn."

Table 3: Course Evaluations.

\begin{tabular}{|c|c|}
\hline Number & Evaluation \\
\hline 1 & The instructor made the subject matter understandable. \\
\hline 2 & The instructor made the subject matter interesting. \\
\hline 3 & The instructor cared about my learning in the course. \\
\hline 4 & The instructor motivated me to learn. \\
\hline 5 & The instructor used the scheduled class time effectively. \\
\hline 6 & The work I did in this course contributed to my learning. \\
\hline 7 & The course contributed to my intellectual growth. \\
\hline
\end{tabular}




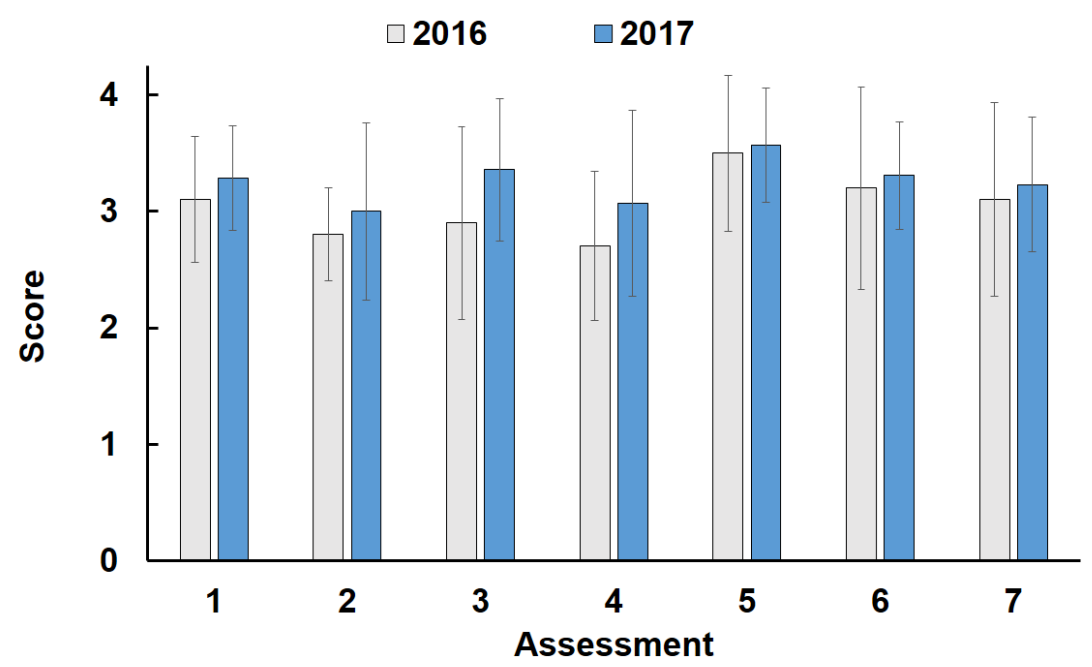

(A)

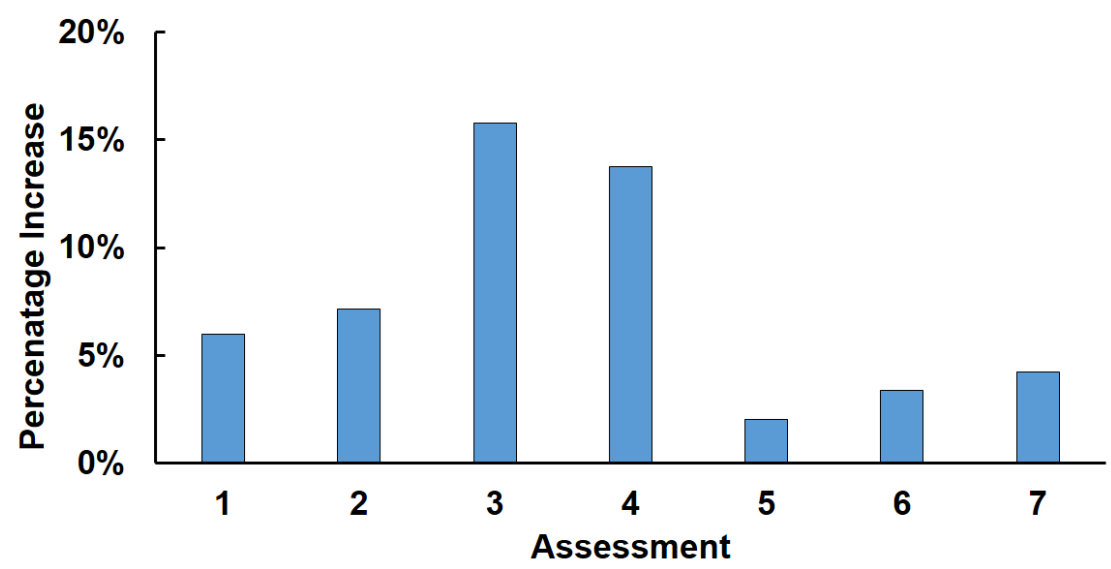

(B)

Figure 9: Comparison of 2016 and 2017 course evaluation in general show improvement under the new course structure (A). The greatest percentage increases were observed in assessments 3 and $4(B)$.

\section{Discussion}

Teaching a highly information-driven course presents challenges to student engagement, especially when this course is taught to seniors during their final semester. Prior experience teaching this manufacturing course motivated the redesign of the structure presented in this paper. From an instructor standpoint, the new course structure required more preparation time, but was more enjoyable and rewarding in the end. The students also seemed to benefit from the new structure both in their learning and engagement. Broadly speaking, the new course structure created a learning environment in which students learned the material (Fig. 7), appreciated the specific course components (Fig. 8) and felt more motivated to learn than those from the previous year (Fig. 9). 
Overwhelming, student surveys revealed a preference for the online-based learning resource, THORS Academy, to the use of a typical manufacturing textbook. While only a small data point, this result seems to agree with other studies indicating a student preference for a greater incorporation of technological resources as learning tools [5-7]. Post-Assessment scores were significantly greater than Pre-Assessment scores indicating knowledge retention by the student following the Course Content modules. A more thorough assessment is needed to determine long-term retention of the content in larger populations. While the experiences using THORS were positive, it is not yet clear whether the most appropriate use of THORS is as a replacement or as a supplement to a traditional manufacturing textbook.

While broad conclusions may be drawn from the data presented, the study is limited by low course enrollment numbers which reduced the statistical significance of the findings. Because of this, it is difficult to isolate the effect of the individual course components from the students' personal opinion of the instructor when analyzing the course evaluation data. As such, one student with either a low or high opinion of the instructor could significantly sway the data. The small class size, however, allowed for an easy integration of the new course components. Scaling up to the needs of larger course enrollments could be both difficult and resourceintensive. This would be especially true for the the hands-on component of the course.

The broad changes to the course structure and content delivery presented in this paper represent a first attempt to address student engagement and motivation in this manufacturing course. Future iterations of the course will continue to address these issues. For one such change, the course would benefit from a more diverse offering of THORS courses. This could be implemented through a combination of assigning more courses, assigning shorter courses, and assigning only subsections of the longer courses. Additionally, the fabrication lab component could be expanded to include other processes. With the growing popularity of AM, students should also be trained to use this technology. Many other papers have already discussed the benefits of integrating AM into undergraduate courses [14-15]. Finally, the end goal is for the course to be taught as a fully "flipped" course. Under this paradigm, content relating to each manufacturing processes would be delivered through an online course. The timing of these online courses would correspond to a hands-on experiences during the scheduled lecture, which could include fabrication labs, facility tours, or problem-based learning activities.

\section{Acknowledgments:}

The author would like to thank Senthil Kumar at THORS eLearning Solutions for providing student Pre-Assessment Scores and average times to complete the THORS courses.

Additionally, the author thanks Laurel Kuxhaus at Clarkson University for original development of the TED Talk presentations.

\section{Disclosure statement:}

Since the acceptance of the original abstract, the author has signed a consulting agreement with THORS eLearning Solutions to advise on adapting the THORS course to better serve academic institutions. 


\section{References}

[1] Bureau of Labor Statistics, "Occupational Employment and Wages - Mechanical Engineers." United States Department of Labor, May 2016. [Available online:

https://www.bls.gov/oes/current/oes172141.htm

[2] Center for Manufacturing Research, "Ohio Manufacturing Facts." National Association of Manufacturers, March 2017. [Available online: http://www.nam.org/Data-and-Reports/StateManufacturing-Data/State-Manufacturing-Data/April-2017/Manufacturing-Facts---Ohio/]

[3] Fink, LD. Creating Significant Learning Experiences: An Integrated Approach to Designing College Courses. San Francisco, CA: Jossey-Bass, 2013.

[4] M. Menekse, G. Stump, S. Krause, M. Chi, "Differentiated Overt Learning Activities for Effective Instruction in Engineering Classrooms."Journal of Engineering Education, vol. 102 (3), pp. 346-374, 2013.

[5] - C. Spezia, D. Thomas, "Tool, Techniques and Class Experience with On-Demand Multimedia Content in an Electric Machines Course," in Proceedings of the 2012 American Society for Engineering Education Annual Conference \& Exposition. June 10-13, 2012, San Antonio, Texas, American Society of Engineering Education, 2012.

[6] H. Sheybani, G. Javidi, "Teaching an Online Technology Course Through Interactive Multimedia," in Proceedings of the 2005 American Society for Engineering Education Annual Conference \& Exposition. June 12-15, 2005, Portland, Oregon, American Society of Engineering Education, 2005.

[7] K. Williams, and C. Williams, "Five Key Ingredients for Improving Motivation," Research in Higher Education Journal, vol. 12, pp. 1-23, 2011.

[8] THORS eLearning Solutions - Thors Academy. [Accessed online Feb. 2018: https://www.thors.com/academy]

[9] THORS Academy, “Turning Fundamentals.” [Accessed online Feb. 2018:

https://academy.thors.com]

[10] C. Brame, "Flipping the Classroom," Vanderbilt University Center for Teaching. [Accessed online Feb. 2018: https://cft.vanderbilt.edu/guides-sub-pages/flipping-the-classroom/]

[11] N. Savage, R. Birch, E. Noussi, "Motivation of Engineering Students in Higher Education," Engineering Education, vol. 6 (2), pp. 39-46. 2015.

[12] TED [Available online: https://www.ted.com]

[13] L. Kuxhaus, "Best Practices in Teaching Biomechanics," in 2016 Summer Biomechanics, Bioengineering, and Biotransport Conference. June 29-July 2, 2016, National Harbor, Maryland. 
[14] T. Serdar, "Education Challenges in Design for Additive Manufacturing," in Proceedings of the 2016 American Society for Engineering Education Annual Conference \& Exposition. June 26-29, 2016, New Orleans, LA, American Society of Engineering Education, 2016.

[15] T. Tseng, A. Akundi, and R. Chiou, “ Technology Integration Across Additive Manufacturing Domain to Enhance Student Classroom Involvement," in Proceedings of the 2016 American Society for Engineering Education Annual Conference \& Exposition. June 26-29, 2016, New Orleans, LA, American Society of Engineering Education, 2016. 